\section{PARTICIPATORY ACTION RESEARCH IN COMMUNITY FORESTRY: A CASE STUDY OF A COMMUNITY FOREST USERS' GROUP FROM A HILL VILLAGE OF EASTERN NEPAL}

\author{
Laya Prasad Uprety*
}

\subsection{The Context and Introduction}

Traditionally, forests in Nepal are managed by the user communities as the "common property resources" and the government, recognizing this historical fact, has formulated the national policy of handing over the forests to the willing communities for their sustained management and utilization. The forests are "common property resources" because a group of users share rights and duties towards them. The institutional arrangements exclude the non-contributing beneficiaries from the "common pool resources". In fact, they are not the "openaccess resources." The user group has the collective responsibility for its conservation. Currently, the community forestry in Nepal is also being managed in accordance with the theories common property resource management.

The Centre for International Forestry Research (CIFOR) had conducted the Adaptive and Collaborative Management $(\mathrm{ACM})$ research in the community forestry in Nepal for a period of two and half years beginning from the middle of 2000 until the end of 2002. This was a part of the overall ACM research being co-ordinated by CIFOR in various Asian (Nepal,

Mr. Laya Prasad Uprety is the Lecturer in Anthropology at the Central Department of Sociology and Anthropology, University Campus, TU, Kirtipur and is currently pursuing his Ph.D in Anthropology.
Indonesia, and the Philippines) and African countries (Ghana, Cameroon, Zimbabwe and Malawi) countries. The ACM research in Nepal was a formal collaboration of the Ministry of the Forests and Soil Conservation (MOFSC), CIFOR and other three research organisations, namely, New ERA, NORMS and Forest Action Group. The Nepal component of ACM research included policy research at the national level and participatory action research at the users' level.

$\mathrm{ACM}$ is rooted in collaborative management techniques that are increasingly being applied today in various fields of natural resource management. This more inclusive approach is gaining favour out of a growing consensus that without some basic agreements among all the affected parties (stakeholders) about how and for what purpose the resource is maintained, sustainability cannot be achieved and degradation will continue. At the same time, ACM draws on models of yet another decision-making process that is gradually being adopted in natural resource planning and adaptive management. The approach is iterative, it provides for regular analysis of progress toward established objectives, and calls for adjustment where necessary in response to changing circumstances. ACM has been taken as a vision and a concept of management. Adaptive collaborative management is a means or a combination of means, that can help achieve sustainable forest management (CIFOR, 2001:I). ACM aims at focusing on the conditions leading to both the improved human well-being and to the maintenance of forest cover and diversity approaches encouraging sustainable use and management of forest resources and impacts of ACM processes and outcomes on people and forests with respect to the different ways that stakeholders act and learn together.

The vision of CM research in Nepal is the well-being of diverse women, men and children involved in the management of forest resources and their sustainability. The goal of ACM research in Nepal is to increase the effectiveness, efficiency and equity of stakeholder relations and management practices through enhanced shared institutional learning and adjustment of management (i.e. collaboration and adaptiveness) in order to 
promote sustainable forest management and well- being of diverse women, men and children.

ACM research in Nepal began in the middle of 2000 . Two research organisations, namely, New ERA and WATCH (now NORMS), started conducting the research in two districts of Nepal. After extensive consultation with the government stakeholder, Sankhuwasaba hill district was selected by New ERA from the eastern development region of Nepal. There two Community Forestry Users' Groups (CFUGs) were selected for the research. These comprised Manakamana and Andheribhajana CFUGs. Similarly, the another research team affiliated with WATCh, after the extensive consultation with government stakeholder, also selected Kaski, a hill district in the western development region of Nepal. These two CFUGs, namely, Bamdi and Hanspur, were selected for the research. These sites were selected by using the criteria developed in the ACM Methodological Workshop held at Bogor, Indonesia, from 28 February to 9 March 2000. The site selection criteria included level of conflict (medium), stakeholders (diverse), composition of community (heterogeneous), devolution status (formal/ informal), pressure on forest (number of households and forest area), forest condition (medium), commercial value (high) and social capital (higher number of locally organized groups/institutions).

Participatory action research (PAR) had been a research approach in ACM. Researchers had used comparable research methodological framework to study adaptive and collaborative processes in the context of community-based management. The use of PAR was guided by the assumption that ACM systems, that is, collaborative systems endowed with the structural capacity to generate and adjust to new knowledge, may not exist as such in concrete forested landscape. There may be a need to address the collaborative and adaptive dynamics in a research/problem-solving mode and participatory action research offers a well-established platform for the facilitation role of research in that process. It was in that framework that a range of methods such as prospective (learning by doing) and anticipatory (future scenarios) designed to enhanced shared learning and transformative knowledge among stakeholders had been in use. These included participatory systems analysis, visioning, future scenarios, criteria and indicator (C\&I) based collaborative monitoring, and conflict management (CIFOR, 2000). The participatory research in Nepal had looked at the iterative processes and at their impact on management actions, people and resources.

When New ERA and WATCH were working for the background and PAR study in the selected four sites of the two hill districts, the MOFSC raised the doubt about the representativeness of the small size of sample and the generalizability/extrapolability of the research findings. The time allocated for background study and PAR was one year each but later the PAR period was extended for six more months. Then, CIFOR also pondered over the seriousness of the issue raised by the MOFSC and finally decided to increase the number of research sites. Then, it commissioned Forest Action Group, a local forest-related research organisation, to conduct the comparative case studies using the conventional research methodology between May and December, 2001. The studies were conducted in nine different CFUGs of the hill and Terai region of Nepal. The objective of this commissioned study was to explore, assess and synthesise the knowledge and experiences of adaptiveness and collaboration at the CFUG field level across a range of community forest (CF) sites and contexts in Nepal. The outputs of this review were intended to enable forest stakeholders in Nepal to draw more easily on the wealth of existing knowledge so that they may make even more informed decisions in designing their forest management process. The study was conducted on five interconnected topics, viz, local stakeholders in community forestry and patterns of their collaboration, social learning and adaptive management, costs and benefits of adaptive management and equity implications, adaptive approach, livelihoods and bio-diversity conservation, and facilitating adaptiveness and collaboration. This was the context of the ACM research.

The present paper is based on the Manakamana CFUG where PAR was carried out. It is in ward no. 12 of Khadbari 
municipality of Sankhuwasabha district. Though it is in the municipality, it possesses predominantly the rural agrarian characteristics. The forest area is 132 hectares. It is a natural forest. The number of the user households is 164 with a total population of 879 . Anthropologically speaking, there is heterogeneity in the composition of the user households. Brahmins, Chettris, Tamangs, Rais, Magars, Gurungs, Limbus, Newars ,Majhis and Kumals are the different caste/ethnic groups. The forest has been formally handed over to the CFUG by the District Forest Office.

The objective of the paper is to analyse the noneconomic benefit/impact of the participatory action research (PAR) as perceived by the ACM researchers and members of the CFUG. In fact, it was a research on participatory action research and in doing so, a myriad of data collection techniques were used, which comprised focus group discussion, key informant interview, group discussion, review of the CFUG records and ACM monthly reports, etc.

\subsection{ParticipatoryAction Research: Conceptual Understanding}

Participatory research can be defined by different levels and types of local involvement of local stakeholders in and control over the research process. It also encompasses different methods, tools and approaches. It includes such methodologies as Participatory Rural Appraisal (PRA), Participatory Action Research (PAR), and Farmer Participatory Research (FPR). The rationale for using the participatory research is to encourage community participation in order to improve the usefulness of research to local people (McAllister, 1999:7). Another reason may be for empowerment or social transformation to strengthen the local people's capacity in decision-making in research, and in management of local resources, in order to improve their awareness of options and to strengthen their ability to act on their own behalf (Ashby, 1996:16-17).

Given the fact that different social groups have different knowledge about natural resource management and different priorities, it is imperative to speak about these social groups in the community (women, men, poor, landless, different ethnic and social status groups, etc) with the objective of understanding the different social perspectives because there are a myriad of social issues in natural resource management. These comprise conflicting social entitlements/ traditional norms, social identities, relationships and roles, different inside and outside stakeholders having values, perceptions and objectives, representation of "community interests" and "knowledge" in participatory research process, power differences between community and outside groups and differences in social power and resource rights between men and women (gender analysis). Daniel Selener, in his treatise, 'Participatory Action Research and Social Change' (1997), clearly explicates the raison d'etre of conducting the participatory action research to induce change. Participatory research is thought to catalyze social change by increasing local awareness of problems and issues, encouraging them to collect, organize and analyze information relevant to their situation, mobilizing them to develop their own options and plans for dealing with problems, and strengthening local capacity and options to act on those plans. The short-term goal of mobilizing local people to solve immediate practical problems is intended to lead to long term shifts in power relations in favor of marginal groups within communities and between the community and governments (Selener, 1997). Indeed, under the traditional research, the researcher sets agenda, controls and undertakes research activities and finally, he benefits from the results. Hopefully, community interviewees will indirectly benefit in the long run. Capacity of the community (social capital) is underestimated and people are separated from process and results of research. This does happen even if the research is conducted using the PRA tools which are increasingly being misused by the inexperienced/untrained field researchers. Conversely, participatory action research (PAR) recognizes the social capital of the community. Under PAR, the researcher and the community identify the problems together. Activities are planned, implemented, monitored and evaluated together. PAR has to focus more on community empowerment, that is, 
strengthening social capital such as networks and local organizations and institutions.

\subsection{Methods Used in Participatory Action Research and their Impact/Benefit}

This section primarily dwells on the methods used in PAR and their local impact/benefit. As analyzed in the preceding section, it has been increasingly recognized that participatory research does encourage the involvement of local people with the objective of improving the effectiveness of the research and enhancing its usefulness for the community. The goal of "empowering" participation is to empower marginalized people and communities by strengthening collective and individual capacity and decision-making power within wider society (Selener, 1997). Given the fact that there is high control or ownership over the research process, local people make decisions with the help of the researchers, implement activities, analyze information and use the research for their purpose. There is collective decision-making and negotiation for the improvement of the existing condition.

With the above theoretical considerations in mind, the ACM researchers in the PAR of Manakamana had used an array of research methods. These comprised visioning of ideal future, trend analysis (comparison of past trends with ideal future of that issue), problem tree analysis and prioritization, participatory intervention or action (by the community with the help of the researchers), self-monitoring (as a research tool), Tole $l^{l}$ meeting (as a tool), participant observation, semi-structured interview, etc. Visioning exercise done with the facilitation of ACM research team helped the internal stakeholders of CFUG to chart out the ideal future of 10 years for the sustainable forest management. Prior to the PAR, they did not have such experience. The problem tree analysis was also an important method in critically analyzing their forest management-related problems and carefully getting them prioritized for the possible action/intervention. Participatory intervention/action involves all the diverse internal stakeholders for getting it implemented with the underlying objective of inducing the desired change. The intervention included workshops, income generating activities, social development, quiz contest on forest, cross- site visits (between ACM sites), etc. Most importantly, the self-monitoring method had been used as a research tool because the forest users had been monitoring changes from their own work/experimentation and sharing the information with the researchers. The researchers, as in other action researches, had also been tracking down the change process and employing research for the purpose of learning and institutional strengthening. Finally, the local forest users had also been assisted by the researchers for tracking the results of their activities and organizational management decisions.

Participant observation was also an important research method for recording the necessary qualitative information on individual or group domination in the discussions, role of women participation in the discussions, process of decision-making, conflict resolution and other relevant group dynamics. The researchers had also been participating in different meetings with the intention of observing and assessing social interactions between forest users and interest groups. Participation in such events had been providing the researchers with ample opportunity to help the forest users devise the relevant strategies in implementing the activities successfully for their well-being. In the PAR, the Tole meeting had also been used as the research tool. Prior to the PAR, this phenomenon virtually did not exist and there was no micro level assessment of the problems and possible solutions with the active involvement of the Tole users of forest. PAR used it as an effective tool because the forest users of the Tole had been identifying the Tole forest- related problems, prioritizing them and getting the activities implemented. They had also been tracking down the changes when they met. It had also been helping the forest users to solve their micro level (i.e. Tole level) problems more effectively and timely. The researchers had also been conducting the semistructured interviews with different stakeholders or groups of stakeholders of the community forest with the objectives of

Tole is a cluster of houses. 
gaining their perspective. Thus, a number of methods had been used in the PAR for accomplishing the objectives of ACM research. (e.g. well-being of men, women and children and better management of forests in a sustainable way).

The review of the monthly reports of the site prepared by the ACM researchers also showed that PAR had its positive impact on strengthening the communication system/information flow amongst the stakeholders, joint learning/social learning, improving forest management activities (e.g. construction of fire lines), people's understanding of systems perspectives (e.g. how socio-cultural and economic systems are linked to the biophysical system of the forest), reflection (past, present and future using participatory systems analysis), trust-building among the stakeholders, use of CFUG fund for income generation of the poor, transparency and accountability of the committee and exploring possible collaboration.

The researchers of the PAR site held the view that the transformative learning process taking place was the direct function of the collaborative research effort. Given the fact that the micro-level change vis-à-vis building of the social capital of the institution and its members had been possible through the incessant collaborative effort of the local stakeholders and the researchers in a relatively long period of time. They held the opinion that these PAR tools were the most suited ones because they involved the field team and community members in all aspects of the study, the collection of information, and the analysis of the findings. The on-the-spot analysis ensured that gaps in the knowledge/information could be filled immediately before leaving the field. They always believed that these PAR tools/techniques raised people's self- awareness, suggested viable solutions and enabled people analyze complex issues and problems of forest management. They also shared that the methodology was flexible and was used for a short time, which involved low level of cost. They expressed that these were the strengths of the methodology. And they thought that they reached the intended participants, i.e., diverse groups of people. The internal constraint of the use of methodology for the researchers was the limited financial resource (which had direct bearing on the length of time). The constraints for the community people were the busy schedule of the livelihood activities (were forced to steal the time to participate in the research process) and skepticism at the beginning (of whether or not the research would benefit them). However, the rapport built with the community through the use of PAR tools and the emphasis on the problems for their solution worked as the enabling factors for undertaking the research.

The intended benefit of PAR was the sustainable forest management by the user community wherein well- being of the diverse groups (men and women, rich and poor, children, etc.) was ensured. This was being done through intentional learning for social transformation and empowerment with the support of the catalytic agents, that is, researchers. Compared to the traditional studies, more stakeholders and community interest groups had been consulted to increase the level of representation. And the voices of the women and marginal groups had also been heard more than before. There had been regular interactions by the researchers with the different stakeholders of each Tole of the CFUG which was utterly inconceivable in the traditional studies. These were the main strengths of the PAR. But there were also a number of weaknesses being discerned in the PAR. The field observation and interaction with the diverse stakeholders had adduced the confirmatory evidence that all women and economically marginalized social groups were still not being included in the PAR process. This was corroborated by the fact that about a total of 26.8 percent of the user members of the CFUG reported that they were unaware of the PAR process. The constraint of the researcher in PAR was the lack of financial resources to support the community forestry activities asked by the users. In fact, the researchers wanted to reduce the dependency syndrome of the local stakeholders. For the users, project meant the provision of financial support. Sometimes when the urgent community need could not be fulfilled with the support of limited quantity of financial resources, people turned to be unwilling to be participants in the research process.

And the researchers were in awkward condition. The constraint of the community was the conflict of the time for 
livelihood activities and PAR activities. And a few local stakeholders also considered the PAR as alien because they did not receive any tangible benefit immediately as they had seen in other projects. Nonetheless, the regular interaction of the researchers with the diverse stakeholders of CFUG and the relative institutional weaknesses had helped the PAR process get going smoothly.

During the PAR stage, the study had made an effort to empower the women under the transformation-oriented gender analysis. The field data have shown that a total of 263 persons had been mobilized by the ACM research team within a period of 7 months (beginning from February, 2001) for their participation in different institutional development activities such as self-monitoring workshops, cross-site visits, reflection and leadership workshop, awareness-raising workshop and forestrelated quiz contests. The field level data generated from the interview and review of the monthly reports had explicitly demonstrated that women participation in research activities was high, that is, 45.3 percent during the PAR phase) (see Table 1). Every time, the ACM researchers made an effort to enhance the participation of women by making both men and women understood about the crucial and important role of women. Sometimes, women were requested by the researchers to participate even by visiting their homes. They had also always urged the functionaries of the CFUG committee to include women in each of their activities and had now realized that women's participation was as important as the men's participation. Nonetheless, women of the poor wealth group had still not been fully mobilized in the PAR activities - a function of less social mobilization by the ACM researchers and more concern of these poor women for their own livelihood activities and household drudgery. Field visit showed that even the socially and economically marginalized groups were still not fully included in the PAR activities.
Table.1 Relative Quantity of Participation in the PAR Study Activities in Manakamana Community Forest Users' Group by Gender in Sankhuwasabha District (2001).

\begin{tabular}{|c|c|c|c|c|}
\hline \multirow[t]{2}{*}{ S.N } & \multirow[t]{2}{*}{ Types of PAR Activities } & \multicolumn{3}{|c|}{ Participation by Gender } \\
\hline & & $\begin{array}{l}\text { No. of } \\
\text { Males }\end{array}$ & $\begin{array}{c}\text { No. of } \\
\text { Females }\end{array}$ & Total \\
\hline 1. & $\begin{array}{l}\text { Second self-monitoring } \\
\text { workshop }\end{array}$ & 29 & 12 & 41 \\
\hline 2. & $\begin{array}{l}\text { Third self-monitoring } \\
\text { workshop }\end{array}$ & 6 & 7 & 13 \\
\hline 3. & $\begin{array}{l}\text { Tole self-monitoring } \\
\text { workshop }\end{array}$ & 52 & 30 & 82 \\
\hline 4. & $\begin{array}{l}\text { Cross-site visit during } \\
\text { second self-monitoring } \\
\text { workshop }\end{array}$ & 2 & 2 & 4 \\
\hline 5. & $\begin{array}{l}\text { Reflection and } \\
\text { leadership workshop }\end{array}$ & 2 & 1 & 3 \\
\hline 6. & $\begin{array}{l}\text { Awareness-raising } \\
\text { workshop }\end{array}$ & 47 & 55 & 102 \\
\hline 7. & Quiz contest & 6 & 12 & 18 \\
\hline 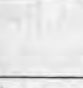 & Total & $\begin{array}{c}144 \\
(54.7 \%) \\
\end{array}$ & $\begin{array}{c}119 \\
(45.3 \%) \\
\end{array}$ & $\begin{array}{c}263 \\
(100.0) \\
\end{array}$ \\
\hline
\end{tabular}

Source: Fieldwork, November, 2001.

\subsection{Researchers' Perceptions on the Benefits of Participatory Research}

The ACM researchers shared that the intended benefits comprised increased collaboration between and among the internal stakeholders, development of the institutional networking, transformative learning and resolution of conflicts between and among individuals and different Toles. The costs included the time of the users for the participation in selfmonitoring activities, Tole level meetings/discussions, awareness creating workshops, quiz contests, facilitation skill training to the Tole coordinators (planned), excursion to successful CFUGs , income generation activities, etc. The researchers thought that these benefits would be generated only through the catalyzation of the CFUG to make the users participative in the research process. 
The informal sharing of the information by the researchers was thought to have its influence on community benefits by improving the weak areas (as analyzed earlier on). The researchers had thought that the local stakeholders would also generate their own findings through the process of participation. In other words, the interactive process among the local stakeholders would generate new findings among them, which would be possible through reflection. The effect would be the better functioning of the CFUG in general and committee in particular.

The ACM research team did the facilitation of the second self-monitoring workshop organized in February, 2001. The CFUG had already gone through the first self-assessment process with the support of district forest office and Nepal-UK Community Forestry Project (NUKCFP). Hence, the general objective of the workshop was to activate on-going learning process which encouraged reflection to apply its learning for the continual improvement of forest and natural resource management and people's life condition. Since the CFUG had already started the process, it was very important to maintain a sense of shared ownership of the workshop and future activities without disturbing existing ownership feelings. The other specific objective were to: (i) revisit the self-assessment process that the CFUG followed to develop the criteria and indicators during the previous workshop and add to an exploration of the concept of learning and monitoring approach to forest management; (ii) review the indicators developed previously and assess their strengths and weaknesses and revise them as needed; (iii) conduct mini-assessment using indicators and exploring strengths and weaknesses; (iv) prioritize issues for action; and (v) develop concrete action plan.

A total of 41 participants (12 females and 29 males) took part in the workshop. During the early hours of the first day of the workshop, it came to be realized by the participants that the first self-monitoring workshop had many shortcomings in the process that led to wrong assessment of indicators. And they also realized that their assessment also did not reflect the actual situation of community forestry. Therefore, it was essential to revisit the self-assessment process and to review indicators so that users would realize the mistakes they made. The participants realized that they did the self-monitoring without the visioning exercise and there was the mismatch between the issues identified and prioritized action points. In fact, the action points the committee had decided to work on were different from the issues to be addressed as identified by users present during the workshop. In fact, the participants did eventually realize that they had not understood the actual meaning and importance of self-monitoring process.

The researchers also shared that the goal of the workshop was also to instill the idea among the participants that self-monitoring is a tool for adaptive and collaborative approach to forest management (that is, vision statements and indicators as tools for monitoring progress towards goals, which enable reflections to contribute to new understanding to adjust and improve management). The games played during the workshop also helped the participants to understand the basic concept and importance of adaptive and collaborative management of community forest and natural resources. The participants did recognize their strengths and weaknesses during the period of game play. They came to the conclusions that each failure was an opportunity to learn and devise collaborative strategies to be successful.

The ACM team facilitators had prepared the selfassessment chart for five vision statements containing three to five indicators (in each vision statement). Ranking of indicators was done on the basis of four different phases of the moon ranging from the new moon to full moon (both being two extremes). New moon meant no achievement or very little achievement in the indicator whereas full moon stood for full achievement. The facilitators explained in brief by demonstrating one self-assessment chart and scoring method. And the participants were divided in five different groups for scoring the indicators of five vision statements separately. They did the scoring in the groups after a protracted discussion. Finally, each group presented the scoring sheet in the plenary and the participants had the heated discussion provided they disagreed 
with the scoring to certain indicators. There was also a realization that the users had to do a lot for improvement of the performance of the indicator that were scored in new moon of the first phase of the moon.

The workshop facilitated by the ACM team also made the participation clear on the issue of prioritization. Indicators that were scored with new moon or the first phase of moon were considered as weak areas (issues) that need to be addressed by the CFUG. But it was not possible to address them at a time. Hence, they were helped for prioritizing them on the basis of their immediate need of their solution. Thus, they also learned the prioritization of issues. Finally, the ACM team also helped them for doing action planning. While facilitating the action planning process, the participants were asked to brainstorm on the past history regarding the issue, supporting and hindering factors, alternative options (that would provide more learning opportunities on the basis of adaptiveness and collaborativeness), anticipated problems and strategies to address them and action plans (indicating activities, their commencement, approach to work, actors responsible, potential problems and possible solutions).

In fact, the benefit of self-monitoring was for all the CFUG members. Awareness and women empowerment workshop and quiz contest did benefit the women. The income generation activities did benefit mostly the poor households living within the CFUG area. A total of 13 persons did participate in the third self-monitoring process (of which 7 were females and 6 were males) at the committee level. At the Tole level self-monitoring, a total of 52 male members and 30 female members did participate. Similarly, a total of 18 participants did participate in the forest-related quiz contest in six Toles (1 male and 2 females from each Tole ).

Thus, self-monitoring and Tole meeting were used as the research tools. Similarly, participant observation had also been used as another method particularly during the committee meeting, general assembly, Tole and other informal meetings to understand the power dynamics, interactive relationship and domination as well as submission of marginalized interest groups and the individuals. During the interaction with the committee meetings or functionaries of the committee, semi-structured interview was also conducted to arrive at a conclusion for the solution of problems.

Each finding of the PAR activities was communicated to the users in the committee and Tole meeting. During the committee meeting, the members had identified that the new DFID-funded livelihood project had the provision of extending support to the existing CFUGs and had been eagerly waiting for ACM researchers for getting an appropriate modality of possible collaboration. This finding was linked to the ACM approach. Likewise, they had discovered that exchange of opinion and visits between and among the CFUGs greatly contributed to social learning process.

As indicated earlier on, the second self-monitoring workshop worked as a foundation during which a shared ideal vision of the future was developed. People, then, started exploring concepts of collaboration, and learning and monitoring approaches to the community forestry management. Then, they also started exploring criteria and indicators and finally, developed a local set of criteria and indicators based on the vision of the ideal future. They had also started revising C\&I as part of learning and monitoring approach. Using the C\&I, selfassessment was done. They had also identified the strengths and weaknesses and their prioritization. And action plans were formulated on the basis of the prioritized issues. In fact, these were the benefits generated by PAR.

In fact, the contribution provided by the ACM researchers during the second self-monitoring workshop helped the local stakeholders to internalize it in the proper. Earlier, they had given the highest scores to the progress of prioritized issues and there was competition among the different Toles to be first without making the actual progress. This had happened due to the lack of visioning. But during the PAR, there were no more problems in this regard.

It has been argued that if the gender participation improves, it will contribute to the sustainable forest management mechanism. There are empirical evidences in Nepal that once 
women start taking part in forest management activities, particularly in the decision-making process, the condition of the forest will improve and the equity of the distribution of forest products will be ensured. Women are the primary stakeholders because they have close relation to forest for fetching firewood, fodder, leaf litter, etc. Their frequency of visiting the forest is higher than men. Hence, they are more familiar with the community forestry. But there was no gender equity in decisionmaking process at the beginning of PAR in the CFUG studied. It has been recognized that lack of women's participation in forest management and decision-making hinders sustainable forest development and $\mathrm{ACM}$ was being proved as an effective strategy for effective gender participation in community forest management and decision-making process - a function PAR . Ever since the PAR activities had been initiated, the ACM researchers had played a facilitating role in increasing the participation of women in the self-monitoring process which subsequently helped the women to be aware of the importance of their participation in sustainable and equitable forest management. Thus, PAR had been using the transformationoriented gender analysis. Women had been considerably empowered - a function of PAR for building the social capital ( Sharma,2001). For example, they had become increasingly aware of the functioning of the committee, general assembly and Tole committees. They started to speak in the public forum much better than before. The awareness creation and empowerment workshop did really make the local women aware of the roles and responsibilities of committee functionaries and transparency as well as accountability. And as a result, the women members of the CFUG pressurized the secretary of the committee to repay the misappropriated amount of Rs. 39,000 . They voiced that they would not allow to have general assembly taken place until its repayment and it was postponed once for that reason. And finally, the secretary returned the misappropriated amount. This was an example of transformation- oriented gender analysis. Though the greater number of the stakeholders had been mobilized during the PAR, not all economically and socially marginalized groups had been incorporated in the process.

The ACM strategy had also been gradually effective in enhancing the level of meso and micro-level sharing among the stakeholders. There were different types of stakeholders of the CFUGs at district and range post level (meso level) and local level (micro-level). There had been the confirmatory evidences that ever since the ACM team members started working as the facilitators at the four monthly meeting of the range post level co-ordination committee (which used to represents the CFUGs of the range post), it had turned to be a forum of exchanging views on forest management and helping each other for the resolution of the forest boundary and management-related conflicts. The ACM researchers had also inspired the two CFUGs (of New ERA sites) for cross-site sharing, which had been proved to be extremely instrumental for mutual learning the lessons/gaining experiences for practical applications.

\subsection{Local Stakeholders' Perceptions on the Benefits of Participatory Action Research}

Most of the people who participated in the PAR shared that they had been present in the initial two days' second selfmonitoring workshop facilitated by the ACM team. Some had participated both in awareness- raising workshops and quiz contests. People who did not have time and did not have interest and who were not informed did not participate in the PAR activities. Small government job holders and school teachers did not participate. The time of participation ranged from 4 hours to 40 hours. The highest amount of time was spent by those people who spent 5 days in self-monitoring workshops (two days in the beginning and three days in the subsequent one). In fact, the participation of the committee members was definitely higher compared to other forest users. The reported reasons behind the participation were for being aware of forest management, strengthening the committee, developing sense of ownership of the research process and helping the committee people to conserve the forest, developing the ability for continuous self-monitoring for tracking the change. Some 
shared that deep interest in the forest conservation, interest in games (played as energizers during the workshop), provision of prizes during the workshop, and the request made by the researchers were the principal factors behind the participation.

The expected benefits were enhanced skills on sustainable forest management and conservation, awareness on the roles and responsibilities of the users towards the forest, understanding of New ERA's role in strengthening the committee in particular and user group in general (as previously done by Nepal-UK Community Forestry Project), possibility of cementing better ties with New ERA for effective forest-related programme implementation in the future, exploration of possibility of increasing the production of non-timber forest products and initiation of the income generation program through the channelization of CFUG fund, etc.

A number of the actual advantages were also reported. For example, the actual advantage from the self-monitoring workshop was the internalization of its very importance for tracking down changes for the sustainable forest management. Increased sense of ownership over the community forestry was another outcome of the participation of the workshop. The games played during the workshop also gave the knowledge to the participation how the internal collaboration would contribute to achieve the desired goal. They realized that the role of the women was also equally important in the conservation of the forest. The importance of the regular reflection was also realized as the actual advantage. Even illiterates were able to participate in the self-monitoring process due to the use of pictorial chart. The gradual disappearance of the fear/hesitation to speak with the outsiders was another advantage from the self-monitoring process/workshop.

The users had a perception that the self-monitoring workshop induced a number of major changes in the CFUGs. These comprised (i) improved communication and consultation between the committee of CFUG and different interest groups within the CFUG; (ii) regularity in committee and assembly meetings; (iii) development of the agreed plan and its effective implementation of the plans; (iv) increased use of CFUG income in social development activities (i.e., income generation for the poor), and (iv) decreasing expectation of the communities for the financial assistance from the donor (because ACM researchers had told them that there was no funding for the CFUG activities and only institutional support was provided). The awareness and empowerment workshop (as indicated earlier on) also helped the women to be bold enough for taking. interest in transparency of the committee activities and became assertive.

The quiz contest helped increase the knowledge of the participants on the community forestry and constitution and operational plan of the CFUG. In other words, they were aware of the rules and regulations of the community forest. The viewers of the programme were also benefited from it. Given the fact that there was the formation of sub-groups at each Tole to lead each separate action plan, each of them learned from its activities and adjusted the activities accordingly. Each group shared its learning and progress with CFUG through semi-annual and Tole meetings and annual development of annual work plans via Tole meetings and assembly. In fact, the agreed prioritized issues and options were selected in the assembly and thus, the micro-level processes were embedded in the macro-level process. This whole process had been giving advantages to the CFUG members.

There had been the perceptions among the stakeholders that the participating stakeholders were better-off in terms of their enhanced capacity (social capital) that could contribute to the effective functioning of their CFUG and its committee. And, in the long run, it would definitely contribute to make the community better off-a function of the enhanced social capital

\subsection{Conclusions}

The participatory action research was geared towards institutional strengthening/empowerment of the CFUGs (including the capacity-building of diverse stakeholders of the group/community) and this was its principal strength. Besides this, the other strengths comprised the relatively high focus on understanding the multiple perspectives/high focus on the quality of participation, greater degree of the reliability of the findings 
(because more intimate contact was maintained for building trust between the researchers and the local stakeholders), more triangulation of the information by talking to a greater number of people in a longer span of time and use of more methods/tools, higher degree of the adaptability of the research approach (for instance, if the self-monitoring system had not worked effectively for the institutional sustainability or if the Tole meetings had not yielded expected results, then the researcher and stakeholders would have devised strategies for the rectification of the weaknesses or used other methods/tools collaboratively), greater emphasis on co-learning (researchers and local people learnt together from each other's activities), dis -aggregation of the collected information for the benefit of stakeholders (e.g. collection of the socio-economic information of the poor/vulnerable households for the initiation of income generating activities), higher degree of the perception of the "ownership" of the research process, more focus on the determination of possible-plausible connection (because effort was always made to look at minutely what factors have triggered the change in the community which was also feasible due to the relatively long stay of the researchers in the community), etc.

Despite the plethora of strengths of PAR, it was also not free from its weaknesses as witnessed in the field. The research, albeit focused on higher diversity of stakeholders, could not be very effective in reaching all the poor men and women - a function of the less orientation of the researchers on the goal of empowering "participation" to "empower" marginalized people and community by strengthening collective and individual capacity and decision-making power within a wider society and less social mobilization by the researchers (Ashby, 1996) and lack of genuine commitment of the researchers and CFUG committee members to empower them. The poor also bore more costs by providing more time (for their longer term benefit) to be utilized for eking out their livelihood.

If "empowerment" is the goal, it is important to strengthen local institutional and individual capacities by involving local people throughout the research process: in problem identification and definition, collection and analysis of information, planning of possible solutions, and in mobilizing local action for change (McAlisster, 1999:5). In fact, the quality of the research also hinges on the competency of the researchers using the participatory methods and hence, it has to be enhanced by enhancing their critical understanding of the limitations and benefits of tools and methods, and increasing their awareness of power and social relations which underlie participatory processes and influence whose perspectives are presented and awareness on how participatory methods do have influence on information and action,

The author wishes to acknowledge Mr. Pradip Poudel and Mrs. Karuna Tamrakar for garnering in the relevant information, Naryan Sitoula and Kalpana Sharma for providing the information, Cynthia McDougall and Mary Milne of The Center for International Forestry Research (CIFOR) for providing the comments in the slightly different version of the paper and New ERA for providing opportunity to work in the $\mathrm{ACM}$ and participatory research and gender analysis projects.

\section{REFERENCES}

Ashby, J.A 1996. "What do We Mean by Participatory Research in Agriculture. New Frontiers in Participatory Research and Gender Analysis". Proceedings of the International Seminar on Participatory Research and Gender Analysis for Technology Development, Sept. 9-14, Columbia.

Campbell, Lorna and Gill, G.T., 1991. Participatory Rural Appraisal for Nepal: Concepts and Methods, Kathmandu: Winrock International.

Centre for International Forestry Research, 2000. The ACM Researchers' Handhook, Bogor, Indonesia.

Chambers, Robert, 1992. Rural Appraisal : Rapid, Relaxd and Participatory. Institute of Development Studies, UK.

McAllister, Karen, 1999. Understanding Participation. IDRC.

Selener, D. 1997. Participatory Action Research and Social Change. New York, Cornell Participatory Action Research Network, Cornell University.

Sharma, Kalpana.2001.Gender Dynamics of Community Forest Management through Collaborative and Adaptive Strategies: A Case Study from the ACM Sites of Sankhuwasabha District, 
Nepal. A Draft Paper Prepared during the Writing Workshop, November 5-19, 2001. CIFOR, Bogor, Indonesia.

Thesis, Joachin and Grody, H.M. 1991. Participatory Rapid Appraisal for Community Development. International Institute for Environment and Development and Save the Children Federation.

Uprety, Laya Prasad.2001. Participatory Research and Gender Analysis Impact Assessment. New ERA, Kathmandu.

Uprety, Laya Prasad, Narayan Sitoula and Kalpana Sharma, 2001. Background Study for Adaptive Co-management: A Final Report Submitted to CIFOR, Bogor, Indonesia. New ERA, Kathmandu.

Uprety, Laya Prasad, Narayan Sitoula and Kalpana Sharma. Adaptive and Collaborative Management in Community Forestry in Nepal: A Final Report of Main Case Studies of Manakamana and Andheribhajana Community Users' Groups of Sankhuwasabha District Submitted to CIFOR, Bogor, Indonesia. New ERA, Kathmandu.

\section{CHANGING PATTERN OF FOREST CONSUMPTION: A CASE STUDY FROM AN EASTERN HILL VILLAGE IN NEPAL}

Binod Pokharel ${ }^{*}$

\section{Preliminary}

This is a longitudinal study on the changing pattern of forest consumption in Belahara Village Development Committee of Dhankuta district for the period 2001 to 1991. The author carried out a follow up study in 2001 and compared it with the results of the study conducted by the author in 1991 for his thesis research in M.A. degree in Anthropology to know the changing behavior of forest consumption in the study area. The follow up study attempts to find out the changing factors associated with forest consumption behaviour of the people. Similarly, this article also compares and contrasts the past and present forest consumption pattern of the study area.

In 1991 there were 750 households (HHs) at the VDC. Out of a total of $750 \mathrm{HHs} 80 \mathrm{HHs}$ were selected for the study. During the period of follow up study, the family members of the same 80 sampled houses were separated from original households for data collection (few of them were found to leave their village and get settled down along the road). The major tools and techniques used in the study were formal/informal

Mr. Binod Pokharel is the Lecturer in Anthropology at the Central Department of Sociology/Anthropology, Tribhuvan University, Kirtipur, Kathmandu. 